\section{Impact of child sexual abuse on mental health}

\author{
Prospective study in males and females \\ JOSIE SPATARO, PAUL E. MULLEN, PHILIP M. BURGESS, DAVID L. WELLS \\ and SIMON A. MOSS
}

\begin{abstract}
Background The lack of prospective studies and data on male victims leaves major questions regarding associations between child sexual abuse and subsequent psychopathology.
\end{abstract}

\begin{abstract}
Aims To examine the association between child sexual abuse in both boys and girls and subsequent treatment for mental disorder using a prospective cohort design.
\end{abstract}

\begin{abstract}
Method Children ( $n=1612$; 1327 female) ascertained as sexually abused at the time had their histories of mental health treatment established by data linkage and compared with the general population of the same age over a specified period.
\end{abstract}

Results Both male and female victims of abuse had significantly higher rates of psychiatric treatment during the study period than general population controls ( $12.4 \%$ v. 3.6\%). Rates were higher for childhood mental disorders, personality disorders, anxiety disorders and major affective disorders, but not for schizophrenia. Male victims were significantly more likely to have had treatment than females (22.8\% v. 10.2\%).

\section{Conclusions This prospective study} demonstrates an association between child sexual abuse validated at the time and a subsequent increase in rates of childhood and adult mental disorders.

Declaration of interest J.S. received an Australian Postgraduate Award. Additional funding detailed in Acknowledgements.
Methodologically, the most compelling evidence to date for an association between a history of child sexual abuse and adverse psychological and social outcomes comes from random community samples, birth cohorts and twin studies (Burnam et al, 1988; Mullen et al, 1994; Fergusson et al, 1996; Dinwiddie et al, 2000; Kendler et al, 2000). Such studies depend, however, on the retrospective ascertainment of child sexual abuse, which creates difficulties, including forgotten or non-disclosed abuse and the reconstruction of abusive experiences to make sense of current distress. Prospective investigations are a rarity and, of these, only two provide data on psychological disturbances and adult mental health (Calam et al, 1998; Horwitz et al, 2001). Additionally, the majority of studies in this area focus exclusively on female subjects (Mezey \& King, 1992), with those that have examined males producing inconsistent findings. This study followed up a large cohort of both boys and girls examined by forensic physicians following allegations of sexual abuse, and ascertained the frequency with which they were subsequently treated in the public mental health services.

\section{METHOD}

\section{The child sexual abuse cohort}

A sample of 1612 children (1327 females, 285 males), 16 years of age and younger, who had been sexually abused were obtained from the records of the Victorian Institute of Forensic Medicine, which carries out all the medical examinations in the State of Victoria in cases of suspected child abuse for the police as well as child welfare and protection services. All subjects included in the study had been born prior to 1991 and after 1950 and had been ascertained as having been sexually abused.

\section{Data linkage}

The child sexual abuse cohort was linked with cases registered on the Victorian Psychiatric Case Register. The Register was established in 1961 and has been described as one of the world's largest psychiatric databases (Eaton et al, 1992). The register records all contacts with public in-patient and community mental health services and currently contains over 500000 names. The register does not include admissions to beds in the private health sector (approximately $6 \%$ of total beds) or outpatient contacts with private providers such as general practitioners and mental health professionals in private practice. The register varies in how adequately it captures different types of mental disorder. The vast majority of those with schizophrenia, or other forms of psychotic disorder, will have contact with public mental health services and appear on the register. Conversely, in affective disorders, only a selected sample of the predominantly more severe cases will be referred to public mental health services and appear on the register.

The case linkage was performed via the implementation of a computer-matching algorithm that extracted potential matches from the child sexual abuse cohort and the Victorian Psychiatric Case Register based on full name and date of birth. This algorithm has been checked against 200 manually rated matches, showing better than $90 \%$ agreement, and two independent raters favoured the algorithm's solutions in every disputed match. Complete psychiatric record details for the matches were then extracted from the Register.

A diagnostic hierarchy was implemented to specify a single diagnosis for cases where multiple diagnoses were recorded. This was to ensure that cases were counted only once. Comorbidity tends to be the rule rather than the exception but is difficult to accommodate within this methodology. The diagnostic categories in order of precedence were: schizophrenic disorders; major affective disorders; organic disorders; other affective and somatoform disorders; anxiety disorders and acute stress reactions; childhood mental disorders; personality disorders; conduct disorders; and alcohol and drug-related disorders. A significant minority of cases had no diagnosis recorded on the register. These cases were largely related to single, or brief, contacts with services, often in the context of a crisis or an emergency department consultation. 


\section{General population controls}

To ensure valid comparisons, the control population employed was restricted to the same age range as cases (1 January 19501 July 1991). To ensure further comparability, the period over which contacts with services were to be examined was restricted to the same specific time period for the two groups (1 July 1991-30 June 2000).

Australian Bureau of Statistics population data were obtained for the 9-year follow-up period (1991-2000) and the estimated resident population of the State of Victoria at 30 June each year for males and females was obtained for this period. The population data by age bands were comparable to the increasing age range of the child sexual abuse cohort in each of the 9 years of follow-up. A growth factor was then calculated for each year and added to the final year population to obtain a single figure for the total estimated resident population in Victoria. The general population estimate was reduced by the number of victims of child sexual abuse, and the control population on the Victorian Psychiatric Case Register by the number of cases of child sexual abuse on the Register.

\section{Ethical issues}

Ethical approval was granted by three independent bodies: the Monash University Standing Committee of Ethics in Research on Humans and the ethics committees of the Department of Human Services and the Victorian Institute of Forensic Medicine.

\section{Statistical methods}

Data analysis was undertaken predominantly using the Statistical Package for the Social Sciences version 10, for Windows. The extent to which continuous variables differed between two groups was analysed using $t$-tests. Chi-squared analyses were conducted to determine whether or not the distinction of some categorical variable varied as a function of another categorical variable. Chi-squared goodness-of-fit tests were conducted to examine gender differences in the predicted and observed frequencies of diagnoses and differences between the child sexual abuse cohort and the comparative samples for each diagnosis. The STATA Release 6 for Windows program was used to obtain relative risks, confidence intervals and $P$ values of the child sexual abuse cohort receiving public mental health treatment and having each of the diagnoses under investigation during the specified 9-year follow-up period. For all analyses the significance level was set at $P=0.05$.

\section{RESULTS}

\section{Sample description}

The mean age of the 1612 subjects when they were examined following allegations of child sexual abuse was 9.4 years (s.d.=4.1). The majority of the sample $(78.3 \%)$ was judged, on the basis of physical examination, to have experienced penetrative abuse. The rates of abuse involving penetration were significantly less for males than for females $(63.2 \% \quad v$. 90.8\%, $\left.\chi^{2}=5.95, P<0.05\right)$. The mean age at the time of data matching for the cases was 27.1 years $($ s.d. $=13.3)$. Males $(n=285)$ had a mean age of 21.3 years (s.d. $=10.2$ ) and females $(n=1327)$ had a mean age of 28.4 years $($ s.d. $=13.5)$.

The estimated population in Victoria born between 1 January 1950 and 1 July 1991 was 3139745 , with males accounting for 1566972 and females 1572773 . The age distribution between cases and controls differed, with controls having a significantly higher mean age for both males and females.

\section{Associations between child sexual abuse and mental disorder}

A record of contact with the public mental health services was found in $12.4 \%$ (135 females and 65 males) of cases between 1 July 1991 and 30 June 2000. There were no significant differences between the age at which the abuse was reported between the 200 individuals found on the Victorian Psychiatric Case Register and those not on the Register. Over the same time period, significantly fewer of the comparison population (3.6\%) recorded a contact (relative risk $=3.8, \quad 95 \%$ CI $3.3-4.4, \quad P<0.001$ ) (Table 1). The rates of contact relative to the control population were significantly greater for both males (relative risk $=7.2$, 95\% CI 5.5-9.6, $P<0.001)$ and females (relative risk $=3.3,95 \%$ CI 2.8-3.9, $P<0.001$ ) (Table 2). Major affective disorders were found more frequently

Table I Comparison between the rates of contact with the public mental health services for various mental disorders in all the child sexual abuse subjects and the general population controls

\begin{tabular}{|c|c|c|c|c|c|c|c|}
\hline \multirow[t]{2}{*}{ Diagnostic group } & \multicolumn{2}{|c|}{ Population controls ( $n=3139745)$} & \multicolumn{2}{|c|}{ Cases $(n=1612)$} & \multirow[t]{2}{*}{ Relative risk } & \multirow[t]{2}{*}{$95 \% \mathrm{Cl}$} & \multirow[t]{2}{*}{$P$} \\
\hline & $n$ & $\%$ & $n$ & $\%$ & & & \\
\hline Schizophrenic disorders & 20792 & 0.7 & 13 & 0.8 & 1.2 & $0.7-2.1$ & NS \\
\hline Major affective disorders & 15143 & 0.5 & 16 & 1.0 & 2.1 & I.3-3.4 & $<0.01$ \\
\hline Other affective and somatoform disorders & 6695 & 0.2 & 7 & 0.4 & 2.0 & $1.0-4.3$ & NS \\
\hline Anxiety and acute stress disorders & 19244 & 0.6 & 31 & 1.9 & 3.2 & $2.2-4.5$ & $<0.001$ \\
\hline Personality disorders & 3350 & 0.1 & 8 & 0.5 & 4.7 & $2.3-9.4$ & $<0.001$ \\
\hline Alcohol/drug-related disorders & 7594 & 0.2 & 4 & 0.2 & 1.0 & $0.4-2.7$ & NS \\
\hline Conduct disorders & 1913 & 0.1 & 7 & 0.4 & 7.2 & $3.4-15.0$ & $<0.001$ \\
\hline Other childhood disorders & 7404 & 0.2 & 29 & 1.8 & 7.7 & $5.4-11.2$ & $<0.001$ \\
\hline Organic disorders & 1947 & 0.1 & 6 & 0.4 & 6.0 & $2.7-13.4$ & $<0.001$ \\
\hline No recorded diagnosis & 29625 & 0.9 & 79 & 4.9 & 5.4 & $4.3-6.8$ & $<0.001$ \\
\hline Total & 113707 & 3.6 & 200 & 12.4 & 3.8 & $3.2-4.4$ & $<0.001$ \\
\hline
\end{tabular}


Table 2 Comparison between male and female victims of child sexual abuse: their rates of contact with public mental health services for various psychiatric disorders

\begin{tabular}{|c|c|c|c|c|c|c|c|c|c|c|c|c|c|}
\hline \multirow[t]{2}{*}{ Diagnostic group } & \multicolumn{2}{|c|}{$\begin{array}{l}\text { Male controls } \\
(n=1566972)\end{array}$} & \multicolumn{4}{|c|}{$\begin{array}{l}\text { Abused males } \\
\qquad(n=285)\end{array}$} & \multicolumn{2}{|c|}{$\begin{array}{l}\text { Female controls } \\
\qquad(n=1572773)\end{array}$} & \multicolumn{4}{|c|}{$\begin{array}{l}\text { Abused females } \\
\qquad(n=1327)\end{array}$} & \multirow{2}{*}{$\begin{array}{c}\text { Abused males } v \text {. } \\
\text { abused females } \\
P\end{array}$} \\
\hline & $n$ & $\%$ & $n$ & $\%$ & RR & $95 \% \mathrm{Cl}$ & $n$ & $\%$ & $n$ & $\%$ & RR & $95 \% \mathrm{Cl}$ & \\
\hline Schizophrenic disorders & 12990 & 0.8 & 3 & I.I & 1.3 & $0.4-4.0$ & 7815 & 0.5 & 10 & 0.8 & 1.5 & $0.8-2.8$ & NS \\
\hline Major affective disorders & 5797 & 0.4 & 2 & 0.7 & 1.9 & $0.5-7.6$ & 9346 & 0.6 & 14 & I.I & $1.8^{*}$ & I.I-3.0 & NS \\
\hline Organic disorders & 1255 & 0.1 & 2 & 0.7 & $8.8^{* * *}$ & $2.1-35.5$ & 692 & 0.04 & 4 & 0.3 & $6.9 * * *$ & $2.6-18.4$ & NS \\
\hline $\begin{array}{l}\text { Other affective and somatoform } \\
\text { disorders }\end{array}$ & 2779 & 0.2 & 1 & 0.4 & 2.0 & $0.3-14.1$ & 3916 & 0.3 & 6 & 0.5 & 1.8 & $0.8-4.1$ & NS \\
\hline Anxiety and acute stress disorders & 8715 & 0.6 & 8 & 2.8 & $5.2 * * *$ & $2.6-10.4$ & 10529 & 0.7 & 23 & 1.7 & $2.6 * * *$ & I.7-4.0 & NS \\
\hline Childhood mental disorders & 5508 & 0.4 & 16 & 5.6 & $16.9 * * *$ & $10.2-27.9$ & 1896 & 0.1 & 13 & 1.0 & $8.2^{* * *}$ & $4.7-14.2$ & $<0.001$ \\
\hline Personality disorders & 1969 & 0.1 & 3 & I.I & $8.5^{* * *}$ & $2.7-26.4$ & 1384 & 0.1 & 5 & 0.4 & $4.3^{* *}$ & $1.8-10.3$ & NS \\
\hline Conduct disorders & 1347 & 0.1 & 5 & 1.8 & $20.8 * * *$ & $8.6-50.3$ & 566 & 0.04 & 2 & 0.2 & $4.2^{*}$ & $1.0-16.8$ & $<0.001$ \\
\hline Alcohol/drug-related disorders & 5648 & 0.4 & $\mathbf{I}$ & 0.4 & 1.0 & $1.0-6.9$ & 1946 & 0.1 & 3 & 0.2 & 1.8 & $0.6-5.7$ & NS \\
\hline No recorded diagnosis & 15440 & 0.9 & 24 & 8.4 & $9.2^{* * *}$ & $6.1-14.0$ & 14185 & 0.9 & 55 & 4.1 & $4.7 * * *$ & $3.6-6.2$ & $<0.01$ \\
\hline Total & 61442 & 3.9 & 65 & 22.8 & $7.2 * * *$ & $5.5-9.5$ & 52265 & 3.3 & 135 & 10.2 & $3.3 * * *$ & $2.7-3.9$ & $<0.001$ \\
\hline
\end{tabular}

RR, relative risk.

$* P<0.05 ; * * P<0.01 ; * * * P<0.001$.

among cases. The anxiety and acute stress disorders were even more strongly associated with child sexual abuse than the major affective disorders, although of the adult diagnostic groupings it was the personality disorders that had the highest relative risk (Table 1). Among the childhood disorders, conduct disorder was associated with child sexual abuse, as was the broader grouping of the other childhood disorders. Those who had contact with the services but never had a diagnosis recorded were significantly more common among cases of child sexual abuse. The rates of schizophrenic disorders, alcohol- and drugrelated disorders and other affective and somatoform disorders did not differ significantly from the general population controls (Table 1). When male cases were compared with male population controls, anxiety disorders, personality disorders, organic disorders, childhood mental disorders and conduct disorders remained significantly higher among cases of child sexual abuse but major affective disorders ceased to be significant. Female cases were significantly more likely than their population controls to be found on the register for major affective disorders, anxiety disorders, personality disorders, organic disorders, childhood mental disorders and conduct disorders, but this was not the case for other affective and somatoform disorders (Table 2).

\section{Comparisons of the period of prevalence for psychiatric contacts in males and females}

Male cases were significantly more likely than female cases to have had contact with public mental health services $(22.8 \% v$. $\left.10.2 \%, \chi^{2}=12.13, P<0.001\right)$. In the category of childhood disorders, males were overrepresented for both conduct disorders (1.8\% v. $\left.0.2 \%, \chi^{2}=13.87, P<0.001\right)$ and other childhood mental disorders $(5.6 \% v$. $\left.1.0 \%, \chi^{2}=27.95, P<0.001\right)$. No significant differences were found between male and female cases for the rates of contact in adult life for specific diagnostic groups such as schizophrenia $(1.1 \% v .0 .8 \%)$ and major affective $(0.7 \% \quad v .1 .1 \%)$, anxiety $(2.8 \%$ v. $1.7 \%)$ and personality disorders $(1.1 \%$ $v$. $0.4 \%$ ), but for the group without a recorded diagnosis the male cases were more numerous $\left(8.4 \% v .4 .1 \%, \chi^{2}=8.72\right.$, $P=0.01$ ).

\section{DISCUSSION}

This study is unique in demonstrating prospectively a clear association between child sexual abuse validated at the time and serious disturbances of mental health in both childhood and adult life. The study population had their sexual abuse ascertained not just by contemporary accounts but also by medical examination, which in the majority was judged to indicate abuse involving penetration. The study documents the associations in male as well as female victims, revealing that although subtle differences may exist in the responses to child sexual abuse between the genders, male victims show associations to most adverse mental health outcomes that are just as strong as those shown in females. Studies on cohorts of this size are a rarity and this is the first study with the potential statistical power to reveal whether the often advanced hypothesis of an association between child sexual abuse and schizophrenia has a basis. The results do not support an association between child sexual abuse and psychosis.

\section{Limitations}

This study has limitations. Those whose sexual abuse comes to official notice at the time are a minority, possibly drawn from among the more severely abused. The outcome measure employed was contact with the public mental health services, which is an extreme indicator of psychopathology. Many people suffer significant mental health problems without seeking professional help, or confine their contact to general practitioners, counsellors or private psychiatrists and psychologists.

The results of this study, therefore, do not give information on the absolute 
frequency of those seeking therapy for the total spectrum of mental disorders. What the study does quantify is the severe and disabling end of the psychopathology spectrum. That nearly four times as many of those in the child sexual abuse group had received treatment in public mental health services is a dramatic indicator of the association between abuse and mental disorder, with its implied impact on mental health services. In a sense, this study documents not the breadth but the depth of the psychiatric problems associated with child sexual abuse.

A systematic bias is introduced by the presence of people who were subjected to child sexual abuse in the general population, which will act to reduce or even obscure the differences between cases and controls. The children in the study cohort were predominantly subjected to abuse involving actual or attempted penetration. This gross form of abuse is sadly not a rarity in our community. Estimates of the prevalence of child sexual abuse involving penetration vary widely but a rate of $5 \%$ is a plausible approximation (Fergusson $\&$ Mullen, 1999; Andrews et al, 2002). Correcting for the bias that this introduces would not just be a matter of making a $5 \%$ adjustment. The preponderance of the evidence about child sexual abuse and adult mental disorder indicates that those who have experienced abuse involving penetration are overrepresented among some mental disorders (Fergusson \& Mullen, 1999; Andrews et al, 2002). Taking major depression as an example where there is at least twice the risk in victims of child sexual abuse, this implies that at least $10 \%$ of those with major affective disorders among the control population will come from those with histories of penetrative abuse. This introduces a major bias against detecting increased associations with mental disorder among the child sexual abuse cohort.

A further systematic bias against detecting higher rates of disorder among those who have suffered child sexual abuse is introduced by comparing child sexual abuse cases established by data-matching with a control population, which is derived from relating all known cases on the register back to the known population base. Data-matching inevitably misses cases because of, for example, technical failures in the matching process, incorrect data entry and people changing their names or giving false names. The comparative data from controls, in contrast, involve no loss of data because the totality of cases is compared with the base population. Further, those in the child sexual abuse cohort who have moved state or country will not be recorded on the register even if they have had treatment in their new abode. In contrast, the control data are calculated from the population known to have been present in Victoria at the time. These various factors introduce powerful systematic biases against finding differences between cases and controls. Conversely, they increase confidence in those associations that do emerge.

\section{Associations between child sexual abuse and mental disorders in adult life}

The systematic biases noted in this study all decrease the probability of finding a positive association between child sexual abuse and mental disorders. Despite this, a nearly fourfold increase in contacts with the mental health services was demonstrated, compared with the general population. Significant increases were apparent for major affective disorders, anxiety disorders, personality disorders and disorders of childhood.

The failure to demonstrate any association with alcohol- and drug-related disorders runs counter to much of the existing literature (Burnam et al, 1988; Fergusson \& Mullen, 1999; Andrews et al, 2002). This could well reflect the influence of the biases discussed above, combined with the influence of our diagnostic hierarchy, which placed substance misuse at the bottom, thus potentially allocating many cases with substance use problems to their comorbid groupings.

There have been suggestions of a link between child sexual abuse and schizophrenia, a hypothesis that has claimed considerable public, if not professional, attention (Sansonnet-Hayden et al, 1987; Briere et al, 1997; Read \& Argyle, 1999). The differences between cases and controls for schizophrenic disorders did not reach significance in this analysis and a discussion of trends is unlikely to be contributory. The findings to date do not support an association between child sexual abuse and schizophrenia. Care must be taken in interpreting this and other negative findings. The average age of our subjects was in the 20 s, thus many have yet to pass the peak years for developing schizophrenia and related disorders. The control group in contrast are an older population and although restricting contacts to the years 1991-2000 controls this disparity to some extent, it by no means removes its potential influence.

Individuals in the child sexual abuse cohort had twice the rate of major affective disorders, which is consistent with the literature, although this literature is based almost exclusively on female victims (Bifulco et al, 1991; Fergusson \& Mullen, 1999). Interestingly, in this study, an increased risk for major affective disorder was confined to female victims of abuse. This gender difference could reflect depressive disorders being more readily evoked by child sexual abuse in females (Horwitz et al, 2001).

An association was found between the category of organic disorder and child sexual abuse. Individuals with organic disorders were more likely to be registered on the Victorian Psychiatric Case Register prior to the abuse being reported, suggesting that these disorders were already present when these individuals were sexually abused. The most likely explanation for this is that children with intellectual and neurological impairments are more vulnerable to abuse. This finding highlights the need to protect children rendered vulnerable by such disabilities from sexual exploitation.

Anxiety disorders and acute stress reactions were the most frequently recorded diagnostic category among victims of child sexual abuse, being equally prominent in males and females. Included in this broad category of anxiety and stress disorders are post-traumatic stress disorders. Individuals in the child sexual abuse cohort were more than three times more likely to be diagnosed with an anxiety disorder or an acute stress reaction. Previous research has focused predominantly on females and these results extend those findings of a positive association to males.

\section{Child sexual abuse and childhood mental disorders}

Childhood mental disorders were significantly more common in the child sexual abuse group with males having an even higher risk than females. The general finding of increased rates of disorders in children was no surprise, although the even greater excess of such cases in male subjects has not been reported previously. Previous research has concentrated on girls where a wide variety of emotional and behavioural 
problems, including depression, anxiety, social withdrawal and somatic complaints, have been described among victims of abuse (Mian et al, 1996). Given the damage that child sexual abuse can cause to a child's self-concept, sense of trust and perception of the world as a relatively safe place, irrespective of gender, it is reasonable to assume that male victims will also experience childhood adjustment difficulties. Indeed, the present investigation demonstrated that childhood mental disorders were the second most frequently recorded diagnostic category on the Victorian Psychiatric Case Register for both males and females in the child sexual abuse cohort.

The present findings on conduct disorders accord with research that has consistently demonstrated higher levels of behavioural problems in sexually abused males compared with females (DarvesBornoz et al, 1998; Horwitz et al, 2001). However, the present study also demonstrated that conduct disorders are significantly more likely in sexually abused females relative to their non-abused female counterparts. Conduct disorders are not exclusive to males and even the higher prevalence of this disorder in males may reflect more a willingness to recognise and refer conduct disorders in boys.

\section{Child sexual abuse and personality disorders}

Individuals in the child sexual abuse cohort had almost five times the rate of a primary diagnosis of personality disorder. This finding is consistent with existing research on child sexual abuse and personality disorders in adulthood (Goldman et al, 1992; Weiler \& Widom, 1996). Again, the increased vulnerability to personality disorders was not gender specific. It is worth emphasising that the Australian public mental health services, like those in the $\mathrm{UK}$, are predominantly a psychosis service and only the more extreme and disabling forms of personality disorder tend to receive services. Another factor that may have affected the ascertainment of personality disorder in this study was the frequency with which such states are accompanied by depressive or anxiety disorders, which took precedence when allocating to a diagnostic group.

\section{Male and female differences in the association with abuse}

Males and females in the child sexual abuse cohort were both significantly more likely than their gender-matched controls to have had contact with public mental health services. When, however, rates of contact were compared between males and females who had been abused, the males were significantly more likely to have had contact. This runs counter to the assumption often made in the literature that female victims of child sexual abuse are more likely than males to disclose their sexually abusive experiences and subsequently seek treatment (Watkins \& Bentovim, 1992). Counter at least to assumptions about treatment-seeking, care should be taken not to overinterpret this finding. It may well be that females are seeking help more frequently than males from the wide range of mental health services outside of the public system. Possibly the male excess in public mental health contacts relates to their failing to seek help until the situation is so severe that admission or community treatment in the public services is necessary. The excess of males seen in the public child psychiatric services may also reflect a paucity of services for male as opposed to female victims of child sexual abuse outside of the public services. Certainly, in the early years of the period studied, the main providers of such services outside of public child psychiatry were the Centres Against Sexual Abuse, which tended to be more accessible to female clients. This changed dramatically later in the 1990 s as more open and informed attitudes towards male victims of abuse pervaded these service providers. Nevertheless, more males, particularly early in the 1990s, may have been selectively re-routed to public services. Such a trend may also reflect the high rates of conduct disorder among male victims, who may be more difficult to manage in counselling and psychotherapeutically oriented services and therefore more likely to gravitate to the public services as a last resort.

\section{Placing child sexual abuse in context}

This study implemented a prospective cohort design to examine the long-term associations between child sexual abuse and mental illness. No previous investigation into child sexual abuse has prospectively examined such a large sample of males and females subjected to abuse. The study lends powerful support to there being an association between child sexual abuse and adverse mental health outcomes and, more clearly than previous studies, demonstrates that the negative mental health outcomes of abuse are remarkably similar for males and females. The study confirms the increased rates of affective, personality and childhood mental disorders, but gave no support to child sexual abuse being associated with schizophrenic disorders in later life. A greater utilisation of public mental health services among victims of child sexual abuse is also documented.

Child sexual abuse has, for a number of years, occupied a privileged position relative not only to physical and emotional abuse but to the whole gamut of childhood adversity. This study further emphasises the associations specifically between child sexual abuse and adverse mental health outcomes. In our view, however, child sexual abuse often emerges from a nexus of adversity and its impact is mediated by a range of family, social, psychological and biological variables. The doubts about whether there are true associations between child sexual abuse and significant disturbances of mental health both in childhood and in adult life, which continue to be raised (Rind $e t$ al, 1998; Coid et al, 2003), can now be answered unequivocally in the affirmative. It is time to turn our attention to investigating those factors that mediate, and potentially ameliorate, the impact not only of sexual abuse but of the whole range of childhood adversities in order to be able to mitigate the damage that abuse and disadvantage inflicts on children.

\section{ACKNOWLEDGEMENTS}

The linkage study was performed by Strategic Data Pty Ltd, and was jointly funded by Forensicare and the Department of Psychological Medicine, Monash University.

\section{REFERENCES}

Andrews, G., Corry, J., Slade, T., et al (2002)

Comparative Risk Assessment: Child Sexual Abuse (final report). Sydney: St Vincent's Hospital, Clinical Research Unit for Anxiety and Depression (CRUfAD). http: // www. crufad.com/research/sexualabuse.htm

Bifulco, A., Brown, G.w. \& Adler, Z. (1991) Early sexual abuse and clinical depression in adult life. British Journal of Psychiatry, 159, 115-122.

Briere, J., Woo, R., McRae, B., et al (1997) Lifetime victimisation history, demographics, and clinical status in female psychiatric emergency room patients. Journal of Nervous and Mental Disease, 185, 95-101.

Burnam, M. A., Stein, J. A., Golding, J. M., et al (1988) Sexual assault and mental disorders in a 
community population. Journal of Consulting and Clinical Psychology, 56, 843-850.

Calam, R., Horne, L., Glasgow, D., et al (1998) Psychological disturbance and child sexual abuse: a follow-up study. Child Abuse and Neglect, 22, 901-913.

Cold, J., Petruckevitch, A., Chung, W. S., et al (2003) Abusive experiences and psychiatric morbidity in women primary care attenders. British Journal of Psychiatry, 183, 332-339.

Darves-Bornoz, J. M., Choquet, M., Ledoux, S., et al (1998) Gender differences in symptoms of adolescents reporting sexual assault. Social Psychiatry and Psychiatric Epidemiology, 33, III-117.

Dinwiddie, S., Heath, A. C., Dunne, M. P., et al (2000) Early sexual abuse and lifetime psychopathology: a co-twin control study. Psychological Medicine, 30, 4I-52.

Eaton, W. W., Mortensen, P. B., Herrman, H., et al (1992) Long-term hospitalization for schizophrenia: Part I. Risk for rehospitalization. Schizophrenia Bulletin, $\mathbf{1 8}$ 217-228.

Fergusson, D. M. \& Mullen, P. E. (1999) Childhood Sexual Abuse: An Evidence-Based Perspective. Thousand Oaks, CA: Sage.

Fergusson, D. M., Lynskey, M. T. \& Horwood, L. J. (1996) Childhood sexual abuse and psychiatric disorder in young adulthood: II. Psychiatric outcomes of childhood sexual abuse. Journal of the American Academy of Child and Adolescent Psychiatry, 34, 1365-1374.

Goldman, S. J., D’Angelo, E. J., DeMaso, D. R., et al (1992) Physical and sexual abuse histories among children with borderline personality disorders. American Journal of Psychiatry, 149, 1723-1726.

Horwitz, A.V., Spatz Widom, C., McLaughlin, J., et al (200I) The impact of childhood abuse and neglect on adult mental health: a prospective study. Journal of Health and Social Behavior, 42, 184-201.

Kendler, K. S., Bulik, C. M., Silberg, J., et al (2000) Childhood sexual abuse and adult psychiatric and substance use disorders in women: an epidemiological and cotwin control analysis. Archives of General Psychiatry, 57, 953-959.

Mezey, G. C. \& King, M. G. (1992) Male Victims of Assault. Oxford: Oxford University Press.

Mian, M., Marton, P. \& LeBaron, D. (1996) The effects of sexual abuse on 3- to 5-year-old girls. Child Abuse and Neglect, 20, 73I-745.

Mullen, P. E., Martin, J. L., Anderson, J. C., et al (1994) The effect of child sexual abuse on social, interpersonal and sexual function in adult life. British Journal of Psychiatry, 165, 35-47.

\section{CLINICAL IMPLICATIONS}

- This prospective study clearly demonstrates that child sexual abuse is associated with increased rates of a range of mental disorders in childhood and adult life.

- Male victims of child sexual abuse are at least as likely as female victims to show subsequent psychopathology.

- Conduct disorders are significantly more frequently found in both male and female victims of child sexual abuse but males have significantly higher rates than females.

\section{LIMITATIONS}

A systematic bias against establishing higher rates of disorder in victims of child sexual abuse is introduced by the $5 \%$ of the general population controls likely to have been themselves victims of penetrative child sexual abuse.

- Cases of child sexual abuse that come to official notice at the time are a minority, probably drawn from among the more severely abused.

- Treatment in the public mental health services is a very conservative measure of psychopathology.

JOSIE SPATARO, PhD, PAUL E. MULLEN, DSc, Victorian Institute of Forensic Mental Health, Department of Psychological Medicine, Monash University; PHILIP M. BURGESS, PhD, Mental Health Research Institute of Victoria; DAVID L.WELLS, MBBS, Department of Forensic Medicine, Monash University, Victorian Institute of Forensic Medicine; SIMON A. MOSS, PhD, Department of Psychology, Monash University, Victoria, Australia

Correspondence: Professor Paul E. Mullen, Thomas Embling Hospital, Locked Bag 10, Fairfield, Victoria 3078, Australia. E-mail: paul.mullen@forensicare.vic.gov.au

(First received 2 June 2003; final revision 8 December 2003, accepted 6 January 2004)

Read, J. \& Argyle, N. (1999) Hallucinations, delusions, and thought disorder among adult psychiatric inpatients with a history of child abuse. Psychiatric Services, 50, 1467-1472

Rind, B., Tromovitch, P. \& Bauserman, R. (1998) A meta-analytic examination of assumed properties of child sexual abuse using college samples. Psychological Bulletin, 124, 22-53.

Sansonnet-Hayden, H., Haley, G., Marriage, K., et al (1987) Sexual abuse and psychopathology in hospitalized adolescents. Journal of the American Academy of Child and Adolescent Psychiatry, 25, 753-757.

Watkins, B. \& Bentovim, A. (1992) The sexual abuse of male children and adolescents: a review of current research. Journal of Child Psychology and Psychiatry and Allied Disciplines, 33, 197-248.

Weiler, B. L. \& Widom, C. S. (1996) Psychopathy and violent behaviour in abused and neglected young adults. Criminal Behavior and Mental Health, 6, 253-27I. 